appropriate, are all factors that will not only improve outcomes for patients but also enhance job satisfaction for the health professionals who deliver the care.

Now that responsibility for $\mathrm{OOH}$ care in the UK resides with primary care trusts, there are new and improved opportunities for better provision of safe and effective $\mathrm{OOH}$ care for patients and health professionals alike. $\mathrm{OOH}$ care that mitigates both clinical and personal risks as far as possible is best achieved with a well-structured, well-supported, and adequately resourced approach to acute primary medical care.

\section{Susan Pullon,}

Senior Lecturer, University of Otago Wellington, Wellington, New Zealand.

\section{Lynn McBain,}

Senior Lecturer, University of Otago Wellington, Wellington, New Zealand.

\section{REFERENCES}

1. Edwards M, Bobb C, Robinson SI. Nurse practitioner management of acute in-hours home visit or assessment requests: a pilot study. Br J Gen Pract 2009; 59(558): 7-11.

2. Geue C, Skåtun D, Sutton M. Economic influences on GPs' decisions to provide out-of-hours care. $\mathrm{Br} J \mathrm{Gen}$ Pract 2009; 59(558): 12-17.

3. Campbell J, Roland M, Richards S, et al. User's reports and evaluations of out-of-hours health care and the UK national quality requirements: a crosssectional study. Br J Gen Pract 2009; 59(558): 18-23.

4. Noonan T, Arroll B, Thomas D, et al. When should I do rural general practice? A qualitative study of job/life satisfaction of male rural GPs of differing ages in New Zealand. N Z Med J 2008; 121(1283): 59-67.

5. Ingram JC, Calnan MW, Greenwood RJ, et al. Risk taking in general practice: GP out-of-hours referrals to hospital. Br J Gen Pract 2009; 59(558): 24-28.
6. Rossdale M, Kemple T, Payne S, et al. An observational study of variation in GPs' out-of-hours emergency referrals. Br J Gen Pract 2007; 57(535): 152-154.

7. Calnan M, Payne S, Kemple T, et al. A qualitative study exploring variations in GPs' out-of-hours referrals to hospital. Br J Gen Pract 2007; 57(542): 706-713.

DOI: 10.3399/bjgp09X394770

\section{ADDRESS FOR CORRESPONDENCE}

\section{Susan Pullon}

University of Otago Wellington, Primary Health Care and General Practice, 23a Mein St, Newtown, Wellington, 6021, New Zealand. E-mail: sue.pullon@otago.ac.nz

\title{
The contraceptive revolution: some excellent progress but work still to be done
}

By 1960 the world's population had grown to around 3 billion people, having taken just 33 years to increase from 2 billion. ${ }^{1}$ Although many agreed that growth rates needed to fall, couples at the time had few reversible contraceptive choices: mainly barrier methods, spermicides, and a few plastic-only and metal-based intrauterine devices (IUDs). Many relied on 'withdrawal'. This was soon to change dramatically because during the 1950s scientists had patented two synthetic progestogens, norethisterone and norethynodrel. ${ }^{2}$ Clinical studies showed that these hormones inhibited ovulation, although some accompanying oestrogen (initially mestranol, now ethinylestradiol) was needed for acceptable breakthrough bleeding and pregnancy rates. The first combined oral contraceptive was marketed in the US in 1960, and in the UK the following year. Many women enthusiastically embraced 'the pill'; for some because it separated contraception from the act of intercourse and for others because it could be used without their partner's knowledge. Early on, however, concerns were expressed about the method's carcinogenic potential, and about reports of associated venous thromboembolic and other cardiovascular events. ${ }^{2}$ Furthermore, the unfolding thalidomide tragedy of the early 1960s provided a powerful reminder of the epidemiological truth that when millions of people use a medicinal product small increases in risk still result in many people affected.

Oral contraception is now one of the most scrutinised medicinal products on the market. Two British investigations that celebrated their 40th anniversaries in 2008 have been major contributors to the evidence base for current clinical practice. Both illustrate the enormous research opportunity of NHS clinical records. The Oxford/Family Planning Association (Oxford/FPA) Study began in 1968, when 17 family planning clinics in England and Scotland started recruiting
17000 white, married women using oral contraception, the IUD or the diaphragm. ${ }^{3}$ The Royal College of General Practitioners' (RCGP) Oral Contraception Study started at the same time, with 1400 GPs throughout the UK recruiting 47000 mainly white, married (or living as married) women, half of whom were using oral contraception. ${ }^{4}$ Both studies have followed up their cohorts through a mixture of clinic or practice reports, personal contact, and the cancer and death notification services of the NHS Central Registries. Each study has provided, in different ways, key insights into the effects of different contraceptives; as well as novel information about other women's health issues. For example, the RCGP study was the first to show that the risk of cardiovascular disease is much higher in pill users who smoke, ${ }^{5}$ especially among older women, and that the risk of hypertension and arterial disease is related to the combined pill's progestogen 
content. ${ }^{6}$ The Oxford/FPA study assessed the effectiveness, safety, and return to fertility after stopping different methods. Long-term mortality ${ }^{3,4}$ and cancer ${ }^{7,8}$ results from both studies have been reassuring.

There have been many changes to the combined contraceptive pill's composition over the years, including reductions in its hormonal content (one daily pill used in the 1960s is equivalent to a week's worth now), and the introduction of new progestogens and novel ways of use. Some of the developments have been aimed at reducing the cardiovascular risks associated with combined oral contraception. Although statistical differences in the cardiovascular risk of various formulations have emerged, most notoriously with respect to venous thromboembolism, ${ }^{9}$ the differences are of limited clinical significance, partly because the background risk of disease is low. Furthermore, the arterial risks of myocardial infarction and stroke can be reduced, if not removed entirely, by the careful selection and monitoring of users, principally with respect to personal and family history of traditional cardiovascular risk factors such as smoking, obesity, and raised blood pressure. ${ }^{10}$

We now have a clearer picture of the cancer risks associated with combined oral contraception. Compared with nonusers, current users have an increased risk of being diagnosed with breast, ${ }^{11}$ cervical, ${ }^{12}$ or hepatocellular cancer. ${ }^{13}$ Hepatocellular cancer is rare in developed countries. The breast and cervical cancer risks decline after stopping oral contraception, returning to that of nonusers within about 10 years. ${ }^{11,12}$ Conversely, combined oral contraceptive users have a reduced risk of endometrial, ${ }^{13}$ ovarian, ${ }^{14}$ and colorectal cancer. ${ }^{13}$ The ovarian and endometrial benefits appear to persist for many years after stopping oral contraception, perhaps more than 15 years. ${ }^{13,14}$ Limited evidence suggests that today's lower oestrogen dose formulations provide similar protection against endometrial and ovarian cancer as older, higher-dose preparations..$^{15,16}$ At least within the RCGP cohort, the long-term cancer benefits appear to counterbalance the short-term harmful ones; indeed there may even be a net public health gain. ${ }^{8}$ Collectively, the research shows that benefits of oral contraception use outweigh risks, when provided appropriately. Importantly, prolonged use of oral contraception does not appear to reduce future fertility. ${ }^{17}$

Contraceptive developments over the past 50 years have not been confined to changes in the combined contraceptive pill. Manufacturers have introduced, and then continuously refined, a range of progestogen-only products, which provide the hormone orally, by injection, intrauterine system (IUS), or within implantable subdermal rods. Transdermal patches, monthly injections and hormonereleasing vaginal rings delivering combinations of oestrogen and progestogen have also been produced. Plastic IUDs were introduced in the 1960 s, to be followed by fixed copper, levonorgestrel-releasing, and frameless copper devices. Barrier contraceptives have evolved with the introduction of polyurethane male and female condoms, and silicone diaphragms. Natural family planning methods have expanded with the development of the Billings (cervical mucus change) method and devices to assist couples following the symptomthermal approach. Women requiring emergency contraception can now chose between a single-dose levonorgestrel pill (available in the UK from community pharmacies without prescription) and the post-coital insertion of a copper intrauterine device.

Current research is likely to expand the range of options further, perhaps through the development of gonadotrophinreleasing hormone antagonists, antiprogesterones, contraceptive vaccines, and male hormonal contraception. It is important to have a range of efficacious, safe, and cost-effective methods as women and men have different contraceptive needs at different stages of their reproductive lives. Excellent technologies, however, are worthless if they cannot be accessed, or are used poorly. Concerns about the safety of different contraceptives have sometimes created medical barriers to the provision of contraception, ${ }^{18}$ a problem not helped by media scares. In an effort to redress the balance, in 1994 the World Health Organization published Improving Access to Quality Care in Family Planning: Medical Eligibility Criteria for Contraceptive Use, ${ }^{19}$ a comprehensive assessment of who can safely use different contraceptives. This was followed in 2002 by Selected Practice Recommendations for Contraceptive Use, ${ }^{20}$ which provided guidance on the safe and effective use of different contraceptives. Both documents have been updated several times, using an increasingly evidence-based approach. Many countries, including the UK, ${ }^{21}$ have adapted the documents for their local circumstances. This work complements other evidence-based practice initiatives, including that of the Fertility Regulation Group within the Cochrane Collaboration. ${ }^{22}$

The world's population is now approaching 7 billion, with the 2050 level projected to be 9.5 billion. ${ }^{1}$ This massive population growth is already putting unsustainable strains on global land, water, energy, and food resources. Although all parts of the world have seen a huge increase in contraceptive usage, at least 200 million women still currently lack access to modern contraceptives. The level of unmet need varies considerably in different parts of the world. ${ }^{23}$ Of the 205 million pregnancies occurring annually around the world, approximately 42 million are aborted, often in unsafe circumstances and often with fatal results or resultant disability. ${ }^{24}$ And an unacceptably high proportion of pregnancies that continue end with the death of either the mother or child (or both), or produce long-term serious morbidity. An estimated additional annual global investment of roughly £2 billion (2003 costs) would meet current unmet contraceptive needs, and so prevent 23 million unplanned pregnancies, 22 million induced abortions, 1.4 million infant deaths, 142000 pregnancy-related deaths, and 27 million disability-adjusted life years among women or their offspring. ${ }^{23}$

Back home, the UK continues to have some of the highest teenage pregnancy and abortion rates in Western Europe. There is clearly still considerable need to 
improve access to good contraceptive services and improve uptake and use of contraceptive methods by both women and men. The contraceptive revolution of the past 50 years has resulted in some excellent progress in the provision of a wide range of safe contraceptives. More work is needed though, before its full potential is realised.

\section{Philip Hannaford,}

NHS Grampian Professor of Primary Care, Foresterhill Health Centre, Aberdeen.

\section{Toni Belfield,}

Specialist in Sexual and Reproductive Health Information, Lyndhurst.

\section{Competing interests}

Philip C Hannaford is guardian of the RCGPs' Oral Contraception Study. The study has received in the past unconditional grants from each of the combined oral contraceptive manufacturers for its work. Philip C Hannaford's academic department has received payments in the past 2 years from Wyeth Pharmaceuticals for lecturing and consultancy advice. Toni Belfield has no competing interests.

\section{REFERENCES}

1. US Census Bureau.

http://www.census.gov/ipc/www/idb/worldpop.html (accessed 1 Dec 2008)

2. Marks LV. Sexual chemistry: a history of the contraceptive pill. London: Yale University Press, 2001.

3. Vessey M, Painter R, Yeats D. Mortality in relation to oral contraceptive use and cigarette smoking. Lancet 2003: 362: 185-191.

4. Beral V, Hermon C, Kay C, et al. Mortality associated with oral contraceptives: 25 year follow of cohort of 46000 women from the Royal College of General Practitioners' Oral Contraception Study. BMJ 1999; 318: $96-100$
5. Beral V. Mortality among oral contraceptive users. Royal College of General Practitioners' Oral Contraception Study. Lancet 1977; ii: 727-731.

6. Royal College of General Practitioners' Oral Contraception Study. Effect on hypertension and benign breast disease of progestagen component in combined oral contraceptives. Lancet 1977; i: 624.

7. Vessey M, Painter R. Oral contraceptive use and cancer: findings in a large cohort. Br J Cancer 2006; 95: $385-389$.

8. Hannaford PC, Selvaraj S, Elliott AM, et al. Cance risk among oral contraceptive users: cohort data from the Royal College of General Practitioner's Oral Contraception Study. BMJ 2007; 335: 651-654.

9. Kemmeren JM, Algra A, Grobbee DE. Third generation oral contraceptives and risk of venous thrombosis: meta-analysis. BMJ 2001; 323 . doi:10.1136/bmj.323.7305.131.

10. WHO Scientific Group on Cardiovascular Disease and Steroid Hormone Contraception. Cardiovascular disease and steroid hormone contraception: report of a WHO scientific group. WHO technical report series: 877. WHO: Geneva, 1998.

11. Collaborative Group on Hormonal Factors in Breast Cancer. Breast cancer and hormonal contraceptives: collaborative reanalysis of individual data on 53297 women with breast cancer and 100239 women without breast cancer from 54 epidemiological studies. Lancet 1996; 347: 1713-1727.

12. International Collaboration of Epidemiological Studies of Cervical Cancer. Cervical cancer and hormonal contraceptives: collaborative reanalysis of individual data on 16573 women with cervical cancer and 35509 women without cervical cance from 24 epidemiological studies. Lancet 2007; 370: 1609-1621.

13. Cogliano V, Grasse Y, Baan R, et al. Carcinogenicity of combined oral oestrogen-progestagen contraceptives and menopausal treatment. Lancet Oncol 2005; 6: $552-553$.

14. Collaborative Group on Epidemiological Studies of Ovarian Cancer. Ovarian cancer and oral contraceptives: collaborative reanalysis of data from 45 epidemiological studies including 23257 women with ovarian cancer and 87303 controls. Lancet 2008; 371: 303-314.

15. Weiderpass E, Adami H-O, Baron JA, et al. Use of oral contraceptives and endometrial cancer risk (Sweden). Cancer Causes Control 1999; 10: 277-284.

16. Royar J, Becher H, Chang-Claude J. Low-dose ora contraceptives: protective effect on ovarian cancer risk. Int J Cancer 2001; 95: 370-374.

17. Farrow A, Hull MGR, Northstone K, et al. Prolonged use of oral contraception before a planned pregnancy is associated with a decreased risk of delayed conception. Human Reprod 2002; 17: 2754-2761.

18. Shelton JD, Angle MA, Jacobstein RA. Medical barriers to access to family planning. Lancet 1992; 340: 1334-1335.

19. World Health Organization. Medical eligibility criterio for contraceptive use

http://www.who.int/reproductivehealth/publications/mec/index.htm (accessed 1 Dec 2008)

20. World Health Organization. Selected practice recommendations for contraceptive use. http://www.who.int/reproductivehealth/publications/spr/index.htm (accessed 1 Dec 2008)

21. Faculty of Sexual and Reproductive Health Care. Setting standards in contraception - Improving sexual health for all. http://www.ffprhc.org.uk/ (accessed 2 Dec 2008).

22. Cochrane Collaboration. Cochrane Reviews - by topic 'Fertility Regulation'. http://www.cochrane.org/reviews/en/topics/64_revie ws.html (accessed 2 Dec 2008).

23. UNFPA, The Alan Guttmacher Institute. Adding it up. The benefits of investing in sexual and reproductive health care. New York: UNFPA, 2004.

24. World Health Organization. Global and regional estimates of the incidence of unsafe abortion and associated mortality in 2003. 5th edn. Geneva: WHO, 2007.

DOI: 10.3399/bjgp09X394789

ADDRESS FOR CORRESPONDENCE

\section{Philip Hannaford}

Section of Primary Care, Foresterhill

Health Centre, Westburn Road, Aberdeen

AB25 2AY.

E-mail p.hannaford@abdn.ac.uk 